\title{
Gambaran Kelelahan Kerja Karyawan PT Paving Meriba Jaya Kelurahan Tavanjuka Kota Palu
}

\author{
Fellysca V.M. Politon, Christine \\ Poltekkes Kemenkes Palu \\ Email: Fellyscavmpoliton@gmail.com
}

\begin{abstract}
Work fatigue is one of the occupational safety and health problems that can be a risk factor for work accidents and can have an impact on decreasing work productivity and decreasing work concentration. In Palu City there are three paving factories, namely PT. Supplier Paving Batako Press Kanstin, PT. Watu Meriba Jaya, and PT. Hammer Split Stone. PT. Watu Meriba Jaya has a total number of workers with a total of 38 workers who are divided into the division of mixing, printing, drying, inising (product refining), as well as making stirrups and drivers. The purpose of this study is to know the description of employee fatigue at PT. Watu Meriba Jaya, Tavanjuka Village, Palu City. The method in this research is descriptive. The sample of this research is 38 employees. The data is processed with Univariate Analysis to show a description of the work fatigue of the employees of PT. Watu Meriba Jaya Tavanjuka Kota hammer and presented in table and narrative form. The results of this study indicate that the most working tenure is 32 people (84.2\%). Most nutritional status was normal nutritional status of 33 people (86.8\%). The most work division is printing 15 people (39.5\%) the highest level of fatigue with the most work fatigue is mild work fatigue 27 workers $(71.1 \%)$ It is hoped that related workers who can cause fatigue, to comply with all the rules that have been set by the company.
\end{abstract}

Keywords: Occupational health, fatigue at work

\begin{abstract}
ABSTRAK
Kelelahan kerja merupakan salah satu permasalahan keselamatan dan kesehatan kerja yang dapat menjadi faktor risiko terjadinya kecelakaan kerja dan dapat berdampak terhadap penurunan produktivitas kerja dan penurunan konsentrasi kerja. Di Kota Palu terdapat tiga Pabrik Paving Yaitu PT. Supplier Paving Batako Press Kanstin, PT. Watu Meriba Jaya, dan PT. Batu Split Palu. PT. Watu Meriba Jaya memiliki jumlah pekerja dengan jumlah total pekerja 38 orang yang terbagi pada divisi pencampuran, pencetakan, pengeringan, inising (penghalusan produk), serta pembuatan behel dan driver. Tujuan penelitian ini adalah diketahuinya Gambaran kelelahan kerja karyawan di PT. Watu Meriba Jaya Kelurahan Tavanjuka Kota Palu. Metode dalam penelitian ini adalah deskriptif dengan. Sampel penelitian ini adalah 38 karyawan. Data diolah dengan Analisa Univariate untuk menampilkan gambaran kelelahan kerja karyawan PT.Watu Meriba Jaya Tavanjuka Kota palu dan disajikan dalam bentuk tabeldan narasi. Hasil penelitian ini menunjukan bahwa masa kerja terbanyak adalah masa kerja baru 32 orang (84,2\%). status gizi terbanyak adalah status gizi normal 33 orang $(86,8 \%)$. Divisi kerja terbanyak yaitu percetakan 15 orang $(39,5 \%)$ tingkat kelelahan tertinggi dengan kelelahan kerja terbanyak yaitu kelelahan kerja ringan 27 pekerja $(71,1 \%)$ Diharapkan bagi pekerja yang terkait yang dapat menyebabkan kelelahan, agar mematuhi segalah aturan yang telah di tetapkan oleh perusahaan.
\end{abstract}

Kata kunci: Kesehatan kerja, kelelahan kerja 


\section{PENDAHULUAN}

Kegiatan pengembangan industri merupakan faktor dominan dalam strategi pembangunan bangsa dan negara Indonesia terutama dalam menghadapi era globalisasi dan perdagangan bebas Masyarakat Ekonomi ASEAN (MEA). Pengembangan industri melalui berbagai pembangunan gedung dan kegiatan konstruksi mempunyai potensi bahaya besar yaitu terjadinya kecelakaan kerja. Salah satu faktor penyebab utama kecelakaan kerja yang disebabkan oleh manusia adalah kelelahan (fatique). ${ }^{1}$ Kelelahan kerja merupakan salah satu permasalahan keselamatan dan kesehatankerja yang dapat menjadi faktor risiko terjadinya kecelakaan pada saat bekerja. Kelelahan kerja disebabkan banyak faktor baik faktor individu maupun faktor luar individu sepeti lingkungan kerja berupa desain kerja. Kelelahan kerja penting untuk diperhatikan, karena kelelahan pada pekerja dapat berdampak terhadap penurunan produktivitas kerja dan penurunan konsentrasi kerja. ${ }^{2}$

Pengukuran kelelahan terbagi menadi tiga yaitu kualitas dan kuantitas dari hasil kerja kadang kala digunakan sebagai cara pengukuran kelelahan tidak langsung pada industri atau pada tempat kerja. Perasaan kelelahan subyektif metode pengukuran kelelahan subyektif erupakan pengukuran kelelahan berbentuk kuisioner yang berisidari 30 pertanyaan mengenai gejala kelelahan kerja. ${ }^{3}$ Alat ukur perasaan kelelahan kerja merupakan parameter untuk mengukur perasaan kelelahan kerja.alat ukutr yang di gunakan yaitu uji psiko-motor dan uji mental. ${ }^{4}$ Masa kerja adalah suatu kurun waktu atau lamanya tenaga kerja bekerja di suatu tempat. Masa kerja dapat mempengaruhi kinerja baik positif maupun negatif. Memberi pengaruh positif pada kinerja bila dengan semakin lamanya masa kerja personal semakin berpengalaman dalam melaksanakan tugasnya. Sebaliknya akan memberikan pengaruh negatif apabila dengan semakin lamanya masa kerja akan timbul kebiasaan pada tenaga kerja. $^{5}$

Anizar menyatakan bahwa semakin lama seseorang dalam berkerja maka semakin banyak dia telah terpapar bahaya yang ditimbulkan oleh lingkungan kerja tersebut, maka kelelahan yang terjadi akan semakin sering. ${ }^{6}$ Menurut Eraliesa, kelelahan kerja dapat ditanggulangi dengan waktu kerja diselingi istirahat pendek untuk makan,beban kerja tidak berlangsung terlalu lama,tempat tinggal di usahakan sedekat mungkin,disediakan fasilitas rekreasi,pemberian gizi kerja yang memadai dan lain-lain. ${ }^{7}$

Survei Angkatan Kerja Nasional (Sakernas) 2018 mencatat pertumbuhan angkatan kerja di Indonesia cukup besar, yaitu jumlah pekerja pada agustus 2017 adalah 128.062.746 (66,67\%), Agustus 2018 adalah 131.005.641 (67,26\%) dan Agustus 2019 adalah 133.183.869 (67,49\%). ${ }^{8}$ Menurut BPS Kota Palu Sulawesi Tengah pada tahun 2017 memiliki jumlah pekerja aktif sebanyak 1.374.214 dengan pekerja aktif laki-laki adalah 886.072. Khususnya Kota Palu data jumlah pekerja kota palu pada tahun 2017 jumlah pekerja 287.331 orang dan tahun 2018 adalah 292.080 orang.

Di Kota Palu terdapat tiga Pabrik Paving, yaitu PT. Supplier Paving Batako Press Kanstin, PT. Watu Meriba Jaya, dan PT. Batu Split Palu. Pabrik paving yang berlokasi di Kelurahan Tavanjuka, Kota Palu. Perusahaan pancetakan paving tersebut, memiliki jumlah pekerja yang cukup banyak dan terbagi pada beberapa divisi. Dalam proses pencetakan batako tersebut, mulai dari pencampuran, pencetakan, pengeringan dan finishing (penghalusan produk), serta pembuatan behel dan driver. Pengamatan awal yang telah dilakukan di PT. Watu Meriba Jaya, diperoleh jumlah karyawan sebanyak 38 orang, di mana terdiri dari 12 orang bagian pencampuran, 15 orang bagian percetakan, 4 orang bagian pengeringan, 5 orang pembentukan behel dan 2 orang bagian driver. Dari setiap divisi di atas, para karyawan selalu bekerja pada divisi masing-masing setiapa harinya, terkecuali salah satu karyawan tidak hadir, maka pekerja dari divisi lain akan menggantikannya dimana akan terjadi penggandaan (multifungsi) tugas bagi salah satu, atau beberapa karyawan. Dari keterangan di atas, maka peneliti tertarik untuk melakukan penelitian mengenai "Gambaran Kelelahan Kerja Karyawan PT. Watu Meriba Jaya Kelurahan Tavanjuka Kota Palu". 


\section{METODE PENELITIAN}

Jenis penelitian yang digunakan adalah penelitian deskriptif dilaksanakan di PT. Watu Meriba Jaya Kelurahan Tavanjuka., pada bulan Agustus-September 2020 menggunakan sampel jenuh, yaitu total populasi sebanyak 38 karyawan. Teknik pengumpulan data primer melalui pengukuran kelelahan kerja, observasi, dan wawancara dengan menggunakan kuesioner kepada karyawan dan data sekunder yang menyangkut perusahaan termaksud data-data ketenagakerjaan yang ada di PT. Watu Meriba Jaya, Kelurahan Tavanjuka, analisa univariat digunakan dengan tujuan untuk melihat distribusi frekuensi dari varibel yang termasuk dalam penelitian, yaitu gambaran tingkat kelelahan pada karyawan di PT. Watu Meriba Jaya Kelurahan Tavanjuka.

\section{HASIL PENELITIAN}

Penelitian dilakukan di PT. Watu Meriba Jaya Kelurahan Tavanjuka Kecamatan Palu Selatan pada tanggal 16-17 September 2020. Data penelitian diperoleh dengan cara pengukuran lansung mengunakan alat reaction timer, microtoice, dan neraca berat badan. Setelah dilakukan pengolahan data, maka hasil penelitian dapat disajikan secara dekskriptif dalam bentuk tabel sebagai berikut.

\section{Masa Kerja}

Tabel 1. Kelelahan kerja berdasarkan masa kerja pada pekerja di PT.Watu Meriba Jaya Kecamatan Palu Selatan

\begin{tabular}{lccccc}
\hline \multirow{2}{*}{ Masa Kerja } & \multirow{2}{*}{ Frekuensi } & \multicolumn{3}{c}{ Kelelahan Kerja } & \multirow{2}{*}{ Jumlah } \\
\cline { 2 - 5 } & & Ringan & Sedang & Berat & \\
\hline < 5 Tahun & 32 & 23 & 8 & 1 & 32 \\
$\geq 5$ Tahun & 6 & 4 & 2 & - & 6 \\
\hline Jumlah & 38 & 27 & 10 & 1 & 38 \\
\hline
\end{tabular}

Sumber : Data Primer, 2020

Berdasarkan tabel 1 di atas menujukan bahwa lebih banyak karyawan dengan masa kerja kurang dari 5 tahun yang bekerja di PT. Watu Meriba Jaya Kecamatan Palu Selatan atau karyawan masa kerja baru dari pada masa kerja lama.

\section{Divisi Kerja}

Data mengenai divisi kerja yang diperoleh dari hasil wawancara secara lansung dengan mengunakan kuesioner pada Karyawan PT. Watu Meriba Jaya Kecamatan Palu Selatan Tahun 2020 sebagai berikut.

Tabel 2. Kelelahan kerja berdasarkan divisi kerja pada pekerja di PT. Watu Meriba Jaya Kecamatan Palu Selatan

\begin{tabular}{lccccc}
\hline \multirow{2}{*}{ Divisi kerja } & \multirow{2}{*}{ Frekuensi } & \multicolumn{3}{c}{ Kelelahankerja } & \multirow{2}{*}{ Jumlah } \\
\cline { 3 - 5 } & & Ringan & Sedang & Berat & \\
\hline Driver & 2 & 1 & 1 & - & 2 \\
Percetakan & 15 & 12 & 3 & - & 15 \\
Pencampuran & 12 & 8 & 4 & - & 12 \\
Pembentukan behel & 5 & 5 & - & - & 5 \\
Pengeringan & 4 & 1 & 2 & 1 & 2 \\
\hline Jumlah & 38 & 27 & 10 & 1 & 38 \\
\hline
\end{tabular}

Sumber: Data Primer, 2020

Berdasarkan tabel 2 di atas menunjukkan bahwa divisi kerja di PT. Watu Meriba Jaya Kecamatan Palu Selatan dengan karyawan terbanyak terdapat pada percetakan sebanyak 15 orang $(39,5 \%)$ dan karyawan tersedikit pada driver, sebanyak 2 orang $(5,3 \%)$. 


\section{Status Gizi}

Data mengenai status gizi yang diperoleh dari hasil pengukuran secara lansung dengan mengunakan microtoice dan timbangan berat badan pada karyawan PT. Watu Meriba Jaya Kecamatan Palu Selatan Tahun 2020 sebagai berikut.

Tabel 3. Kelelahan Kerja Berdasarkan Status Gizi pada pekerja di PT. Watu Meriba Jaya Kelurahan Tavanjuka

\begin{tabular}{lccccc}
\hline \multirow{2}{*}{ Status Gizi } & \multirow{2}{*}{ Frekuensi } & \multicolumn{3}{c}{ Kelelahan Kerja } & Jumlah \\
\cline { 3 - 5 } & & Ringan & Sedang & Berat & \\
\hline Di bawah normal & 4 & 2 & 2 & - & 4 \\
Normal & 33 & 24 & 8 & 1 & 33 \\
Obesitas & 1 & 1 & & - & 1 \\
\hline Jumlah & 38 & 27 & 10 & & 38 \\
\hline
\end{tabular}

Sumber: Data Primer, 2020

Berdasarkan tabel 3 di atas menujukan bahwa status gizi karyawan di PT. Watu Meriba Jaya Kecamatan Palu Selatan yang terbanyak adalah status gizi normal $(86,8 \%)$.

\section{Tingkat Kelelahan}

Data mengenai tingkat kelelahan yang diperoleh dari hasil pengukuran lansung dengan mengunakan alat reaction timer pada karyawan di PT. Watu Meriba Jaya Kecamatan Palu Selatan tahun 2020 sebagai berikut :

Tabel 4. Distribusi frekuensi berdasarkan tingkat kelelahan kerja di PT. Watu Meriba Jaya Kecamatan Palu Selatan.

\begin{tabular}{lcc}
\hline \multicolumn{1}{c}{ Tingkat Kelelahan } & Frekuensi & Persen (\%) \\
\hline Ringan & 27 & 71,1 \\
Sedang & 10 & 26,3 \\
Berat & 1 & 2,6 \\
\hline Jumlah & 38 & 100 \\
\hline
\end{tabular}

Sumber: Data Primer, 2020

Berdasarkan tabel 4 di atas menujukan bahwa tingkat kelelahan karyawan di PT. Watu Meriba Jaya Kelurahan Tavanjuka Kota Palu terbanyak adalah kelelahan ringan.

\section{PEMBAHASAN}

\section{Masa Kerja}

Berdasarkan hasil penelitian menujukan bahwa Masa Kerja pada Karyawan di PT. Watu Meriba Jaya Kelurahan Tavanjuka Kota Palu Selatan sebanyak 32 orang karyawan dengan masa kerja $<5$ tahun dengan tingkat kelelahan sedang sebanyak 8 orang, berat 1 orang dan ringan 23 0rang. Sedangkan masa kerja $\geq 5$ tahun sebanyak 6 orang karyawan dengan kelelahan kerja sedang 2 orang dan ringan 3 orang.

Beberapa penelitian menunjukkan masa kerja berkaitan dengan kelelahan kerja. Penelitian Merdianto pada tenaga kerja bongkar muat di Pelabuhan Tanjung Emas Semarang menunjukkan adanya hubungan antara masa kerja dengan kelelahan kerja. ${ }^{9}$ Berdasarkan penelitian Mahardika, ada hubungan antara masa kerja dengan kelelahan kerja karena pekerjaan fisik yang dilakukan dalam jangka waktu yang lama akan berpengaruh terhadap mekanisme dalam tubuh. Hal inilah yang menyebabkan pekerja mudah mengalami kelelahan. Masa kerja dapat mempengaruhi kinerja baik positif maupun negatif. Dikatakan, memberi pengaruh positif pada kinerja bila dengan semakin lamanya masa kerja personal semakin berpengalaman dalam melaksanakan tugasnya. Sebaliknya akan memberikan pengaruh negatif apabila dengan semakin lamanya masa kerja akan timbul kebiasaan pada tenaga kerja semakin lama seseorang dalam berkerja maka semakin banyak dia telah terpapar bahaya yang ditimbulkan oleh lingkungan kerja tersebut, maka kelelahan yang terjadi akan semakin sering. ${ }^{10}$ 


\section{Divisi Kerja}

Berdasarkan hasil penelitian menujukan bahwa divisi kerja pada karyawan di PT. Watu Meriba Jaya Kelurahan Tavanjuka Kota Palu Kecamatan Palu Selatan terbagi atas 5 bagian yaitu, 2 karyawan driver (5,3\%), 15 karyawan percetakan(39,5\%), 12 karyawan pencampuran $(31,2 \%), 5$ karyawan pembentukan behel $(13,2 \%)$ dan 4 karyawan pengeringan (10,5\%). Jenis pekerjaan dapat terbagi 2, yaitu pekerjaan ringan dan berat, di mana keduanya dapat berpengaruh terhadap kelelahan kerja. Berdasarkan hasil wawancara, didapatkan hasil bahwa pekerja dalam melaksanakan tugas tidak terpusat pada satu divisi. Apabila ada pekerja yang berhalangan hadir akan digantikan oleh pekerja dari divisi lain sehingga pekerja menjadi multifungsi dalam bekerja.

Beban kerja adalah volume pekerjaan baik berupa fisik ataupun mental yang dibebankan pada pekerja dan menjadi tanggung jawabnya. Pekerjaan yang bersifat berat membutuhkan waktu istirahat yang lebih sering dan waktu kerja yang lebih pendek agar tidak terjadi kelelahan kerja. ${ }^{11}$ Kelelahan kerja dapat dikaitkan dengan beban kerja dan waktu istirahat pekerja yang bersangkutan. Berdasarkan hasil penelitian diketahui bahwa kelelahan kerja berat hanya dialami oleh pekerja dengan beban kerja berat dan sebagian besar pekerja merasa memiliki beban kerja yang berat. $^{12}$

\section{Status Gizi}

Berdasarkan hasil penelitian menujukan bahwa status gizi pada karyawan di PT. Watu Meriba Jaya Kelurahan Tavanjuka Kota Palu Kecamatan Palu Selatan sebanyak 4 orang di bawah normal (10,5\%), 33 orang normal (86.8\%) dan 1 orang obesitas $(2,6 \%)$. Berat badan merupakan salah satu parameter massa tubuh yang paling sering digunakan yang dapat mencerminkan jumlah dari beberapa zat gizi seperti protein, lemak, air dan mineral. Untuk mengukur Indeks Massa Tubuh (IMT), berat badan dihubungkan dengan tinggi badan. Status gizi yang baik dengan jumlah asupan kalori dalam jumlah dan waktu yang tepat berpengaruh secara positif terhadap daya kerja pekerja. Apabila asupan kalori tenaga kerja tidak sesuai dengan kebutuhannya maka tenaga kerja tersebut akan lebih cepat merasakan lelah dibandingkan dengan tenaga kerja yang asupan kalorinya memadai. Asupan kalori yang cukup kemudian digambarkan dengan Indeks Massa Tubuh (IMT) yang normal pada nilai $18,5-25 .{ }^{13}$

Masalah kekurangan atau kelebihan gizi pada orang dewasa (usia 18 tahun ke atas) merupakan masalah penting, karena selain mempunyai resiko penyakit tertentu, juga dapat mempengaruhi produktivitas kerja. Akibat kekurangan zat gizi, maka simpanan zat gizi pada tubuh akan digunakan untuk memenuhi kebutuhan. Bila hal ini berlangsung lama, maka simpanan zat gizi akan habis dan terjadi kemerosotan jaringan, dengan meningkatnya defisiensi zat gizi maka muncul perubahan biokimia dan rendahnya zat-zat gizi dalam darah, berupa rendahnya tingkat $\mathrm{Hb}$, serum vitamin $\mathrm{A}$ dan karoten. Terjadi peningkatan hasil metabolisme seperti asam laktat dan piruvat pada kekurangan tiamin. Bila keadaan ini berlangsung lama, akan mengakibatkan terjadinya perubahan fungsi tubuh dengan tandatanda yaitu kelemahan, pusing, kelelahan, nafas pendek dan lain-lain ${ }^{14}$.

\section{Tingkat Kelelahan}

Berdasarkan penelitian bahwa sebagian besar pekerja mengalami kelalahan ringan terdapat 27 karyawan $(71,1 \%)$, sedang sebanyak 10 karyawan $(26,3 \%)$, dan kelelahan berat 1 karyawan (2,6\%). Diketehui kelelahan terbagi 2 bagian yaitu otot dan umum. Kelelahan otot ialah pengurangan performa dari otot setelah adanya pembebanan dan tidak hanya berdampak pada pengurangan kekuatan tapi juga pergerakan yang lambat, (Syamsuri, 2018). Kelelahan umum ialah sensasi yang disertai dengan perasaan kelambatan dalam melakukan setiap aktifitas.

Berdasarkan hasil pengukuran lansung dengan mengunakan reaction timer pada karyawan normal yaitu pekerja bekerja menggunakan mesin sehingga mempermudah pekerjaan pekerja dan waktu bekerja dimanfaatkan dengan baik. Kelelahan sedang diakibatkan oleh kondisi lingkungan kerja yang bersuhu tinggi sehingga mengakibatkan 
pekerja sering mengeluarkan keringat, mengangkat beban berat yang melebihi kemampuan, menarik/mendorong beban yang berat, serta penyebab Kelelahan yang dialami pekerja di PT. Watu Meriba Jaya menunjukan kondisi yang berbeda-beda dari setiap individu, tetapi semuanya berdampak pada kehilangan efisiensi dan penurunan kapasitas kerja serta ketahanan tubuh.

Kelelahan kerja dapat diketahui dengan melihat adanya penurunan performa kerja atau semua kondisi yang memengaruhi semua proses organisme, termasuk beberapa faktor seperti perasaan kelelahan bekerja (subjective feeling of fatigue), motivasi menurun, dan penurunan aktivitas mental dan fisik. ${ }^{15}$

\section{SIMPULAN DAN SARAN}

Berdasarkan hasil penelitian yang dilakukan di PT. Watu Meriba Jaya Kelurahan Tavanjuka Kecamatan Palu Selatan, dapat disimpulkan bahwa Masa kerja pada karyawan di PT. Watu Meriba Jaya KecamataPalu Selatan didapatkan karyawan dengan masa terbanyak yaitu masa kerja baru 32 orang (84,2\%), Status Gizi terbanyak adalah status gizi normal 33 orang $(86,8 \%)$, Divisi kerja pada karyawan didapatkan bahwa karyawan yang bekerja sebagai driver 2 orang (5,3\%), percetakan 15 orang (39,5\%), pencampuran 12 orang $(31,6 \%)$, pembentukan behel 5 orang $(13,2 \%)$ dan pengeringan 4 orang ( $10,5 \%)$, Kelelahan pada Karyawan menujukan bahwa karyawan dengan kelelahan kerja terbanyak yaitu kelelahan kerja ringan 27 pekerja $(71,1 \%)$, kelelahan sedang sebanyak 10 karyawan $(26,3 \%)$, dan kelelahan berat 1 karyawan (2,6\%). Bagi perusahaan, diharapkan kepada pemimpin perusahaan agar memperhatikan hal hal yang dapat menimbulkan kelelahan pada karyawanya yang bekerja, untuk mencegah terjadinya kecelakaan yang mungkin akan terjadi, Yang bertujuan untuk keselamatan dan kesehatan karyawan, Bagi pekerja diharapkan penelitian ini juga dapat menjadi sumber informasi bagi pekerja yang terkait, yang dapat menyebabkan munculnya kelelahan, dan juga mematuhi segalah aturan keselamatan kerja yang telah di tetapkan oleh perusahaan.

\section{DAFTAR PUSTAKA}

1. Widjasena B, Ekawati E. Hubungan Beban Kerja Fisik Manual Dan Iklim Kerja Terhadap Kelelahan Pekerja Konstruksi Bagian Project Renovasi Workshop Mekanik. J Kesehat Masy. 2016;4(3):425-35.

2. Husna AF. Hubungan antara tingkat pendidikan, pengetahuan dan sikap pekerja terhadap praktik penggunaan alat pelindung pernafasan (masker) pada bagian produksi PT. Pabrik Gula Kebon Agung. J Chem Inf Model. 2016;53(9):1689-99.

3. Latief AWL. Analisis Faktor Yang Berhubungan Dengan Kelelahan Kerja Pegawai PT PLN (Persero) Wilayah Sulawesi Selatan, Tenggara dan Barat. Universitas Hasanuddin; 2017.

4. Roshadi I. Hubungan Kelelahan Kerja Dengan Produktivitas Kerja Karyawan di Fakultas Dakwah dan Komunikasi UIN Sunan Kalijaga Yogyakarta. Universitas Islam Negeri Sunan Kalijaga; 2014.

5. Husni L. Pengantar Hukum Ketenagakerjaan. Jakarta: Rajawali Press; 2015.

6. Anizar. Teknik Keselamatan Dan Kesehatan Kerja Di Industri. Pertama. Yogyakarta: Graha Ilmu; 2012. 86-105 p.

7. Eraliesa F. Hubungan Faktor Individu Dengan Kelelahan Kerja Pada Tenaga Kerja Bongkar Muat Di Pelabuhan Tapaktuan Kecamatan Tapaktuan Kabupaten Aceh Selatan. Skripsi. Universitas Sumatera Utara; 2009.

8. Badan Pusat Statistik. Keadaan Angkatan Kerja di Indonesia Agustus 2018. Jakarta; 2018.

9. Medianto D. Faktor-faktor Yang Berhubungan Dengan Kelelahan Kerja Pada Tenaga Kerja Bongkar Muat (TKBM) di Pelabuhan Tanjung Emas Semarang. Universitas Muhammadiyah Semarang; 2017.

10. Mahardika P. Faktor Yang Berhubungan Dengan Kelelahan Kerja Pada Pekerja Pengisian Tabung Depot LPG PT. Pertamina (Persero) MOR VII Makassar. 
Universitas Hasanuddin; 2017.

11. Suma'mur. Higiene Perusahaan dan Kesehatan Kerja (Hiperkes). Jakarta: CV. Sagung Seto; 2009.

12. Dewi BM. Hubungan Antara Motivasi, Beban Kerja, Dan Lingkungan Kerja Dengan Kelelahan Kerja. Indones J Occup Saf Heal. 2018;7(1):20.

13. Windyananti A. Hubungan Antara Kelelahan Kerja Dengan Stress Kerja Pada Tenaga Kerja di Pengolahan Kayu Lapis Wreksa Rahayu Boyolali. Universitas Sebelas Maret Surakarta; 2010.

14. Atiqoh J, Wahyuni I, Lestantyo D. Faktor-Faktor yang Berhubungan dengan Kelelahan Kerja pada Pekerja Konveksi Bagian Penjahitan di CV. Aneka Garment Gunungpati Semarang. J Kesehat Masy Univ Diponegoro. 2014;2(2):119-26.

15. Bültmann U, Kant I, KasI S V., Beurskens AJHM, Van Den Brandt PA. Fatigue and psychological distress in the working population psychometrics, prevalence, and correlates. J Psychosom Res. 2002 Jun 1;52(6):445-52. 